University of Wollongong

Research Online

Faculty of Social Sciences - Papers (Archive) Faculty of Arts, Social Sciences \& Humanities

2013

Australian children lack the basic movement skills to be active and healthy

Lisa Barnett

Deakin University

Louise Hardy

University of Sydney, louiseh@health.usyd.edu.au

David Lubans

University of Newcastle, david.lubans@newcastle.edu.au

Dylan Cliff

University of Wollongong, dylanc@uow.edu.au

Anthony Okely

University of Wollongong, tokely@uow.edu.au

See next page for additional authors

Follow this and additional works at: https://ro.uow.edu.au/sspapers

Part of the Education Commons, and the Social and Behavioral Sciences Commons

Research Online is the open access institutional repository for the University of Wollongong. For further information contact the UOW Library: research-pubs@uow.edu.au 


\title{
Australian children lack the basic movement skills to be active and healthy
}

\author{
Abstract \\ Just as children need to be taught their ABCs to read and write, they also need to be taught fundamental \\ movement skills (FMS), such as running, jumping, throwing and kicking, to provide the strongest \\ foundation for a physically active lifestyle. Children who are proficient at FMS are more likely to be \\ physically active and have adequate cardiorespiratory fitness, and are less likely to be overweight or \\ obese compared with children who are not proficient. In addition, FMS-proficient children are more likely \\ to become adolescents who are more active and with higher cardiorespiratory fitness levels.

\section{Keywords} \\ children, australian, healthy, active, be, skills, movement, basic, lack \\ Disciplines \\ Education | Social and Behavioral Sciences

\section{Publication Details} \\ Barnett, L. M., Hardy, L. L., Lubans, D. R., Cliff, D. P., Okely, A. D., Hills, A. P. \& Morgan, P. J. (2013). \\ Australian children lack the basic movement skills to be active and healthy. Health Promotion Journal of \\ Australia, 24 (2), 82-84.

\section{Authors} \\ Lisa Barnett, Louise Hardy, David Lubans, Dylan Cliff, Anthony Okely, A P. Hills, and Philip Morgan
}




\section{Australian children lack the basic movement skills to be active and healthy}

3 Just as children need to be taught their ABCs to read and write, they also need to be taught

4 fundamental movement skills (FMS) such as running, jumping, throwing and kicking to

5 provide the strongest foundation for a physically active lifestyle. Children who are proficient

6 at FMS are more likely to be physically active, have adequate cardiorespiratory fitness and

7 less likely to be overweight or obese compared with children who are not proficient $(1,2)$.

8 FMS proficient children are also more likely to become adolescents who are more active (3)

9 and with higher cardiorespiratory fitness levels (4).

11 So what does FMS 'proficient' mean? There are two primary methods to assess children's

12 motor skills; 'product'- or 'process'-oriented. Product assessments measure, for example,

13 how fast a child can run, while process assessments involve the use of observational criteria

14 to determine if the child moves their body to run efficiently, or in a 'proficient' manner. For

15 example, a process assessment of running might look for components such as the whether the

16 arms move in opposition to the legs and with the elbows bent; if there is a brief period where

17 both feet are off the ground; and if the non-support leg bends approximately 90 degrees (5).

19 Regrettably, preschools and schools are limiting children's opportunities to learn and develop

20 proficiency in FMS. Ideally children should develop FMS proficiency during early childhood

21 and primary school through a range of opportunities including unstructured active play (6), interactions with parents, siblings, and caregivers $(7,8)$, quality physical education $(9,10)$,

23 school sport, and community-based programs (11). Yet many children are entering secondary

24 school lacking proficiency in many FMS. Approximately two-thirds of Year 6 children in

25 NSW are not proficient at locomotor skills (e.g. running, jumping and hopping), and two- 
thirds of girls and one quarter of boys have low object control skill proficiency (e.g. ball handling skills such as throwing and kicking) (1). With 85\% of Australian adolescents not meeting the National Physical Activity Recommendations of at least 60 minutes of moderate to vigorous physical activity (MVPA) per day (12) insufficient physical activity (PA) among youth is a global health issue (13). Furthermore one quarter are either overweight or obese (12) and one third do not have adequate cardiorespiratory fitness (14). Therefore urgent action is needed to ensure all Australian children are provided with the opportunity to develop competence and confidence in FMS which will help them to be active, fit, and of a 34 healthy weight.

Schools are universally recognised as important institutions for the promotion of physical activity in young people, with Health and Physical Education (HPE) and school sport programs being key potential vehicles for promotion and provision of physical activity opportunities. However, several recent and significant independent reports have addressed the issue of low levels of physical activity in Australian children and the role of schools in this. In 2009, the Crawford Report (15) highlighted the important role of schools, in particular the need to reinvigorate HPE and school sport in Australian schools. The report states: "It was concerning to learn from experts Australia-wide that the education system no longer reliably provides the platform upon which much of the nation's sporting activity is based. It no longer consistently carries out the vital role of introducing children to physical activity and organised sport" (15). This report identified a lack of teacher training, poor facilities and a low priority for physical activity in schools as major issues. Recommendations pertaining to the school learning context were that sport in schools should be an ongoing priority, physical

49 education a stand-alone learning area, and the national curriculum should be implemented as

50 soon as possible (15). In the same year, the National Preventive Health Task Force 
51 recommended a key strategy within HPE was to promote fundamental movement skills and $m$ that sufficient time was available during school for sport and recreation (16). These

53 findings echoed those of a Senate Inquiry into Sport and PE conducted more than 20 years ago (17).

56 The link between FMS and health outcomes and the low competency levels found in 57 Australian children and adolescents, coupled with the independent reports focusing on these issues, and the impending release of the HPE national curriculum, should provide a catalyst for change. Unfortunately, there exists a policy situation that does not reflect the importance of children developing confidence and proficiency in FMS. For pre-school-aged children, the

61 National Physical Activity Recommendations state "it is important to provide opportunities to practice locomotor, stability and object control skills" (18), but the Australian Government Healthy Eating and Physical Activity Guidelines for Early Childhood Settings and national quality standards for early childhood education do not specify FMS development as a curriculum requirement $(19,20)$. Given the clear evidence of the importance of developing FMS proficiency during childhood, and its importance as a foundation for a physically active life, we strongly recommend that within the broader mandate for increasing the physical activity of Australian children, that FMS development be more clearly specified in all

69 relevant policy documents.

While policy is important, it is only the first step. We need to take urgent action and implement change through both early childhood and school education settings. Assisting the early childhood sector to include FMS development programs is prudent to ensure all children enter school with basic FMS proficiency. We have good available evidence-based programs which target FMS development that are efficacious, translatable and scalable for 
the early childhood sector to integrate. Examples include Tooty Fruity Vegie in Preschools

$77(21,22)$, found to have long-term beneficial outcomes $(23,24)$ and successfully translated across NSW as Munch and Move'(25) and Jump Start (26); currently being translated in childcare settings in Tasmania.

80

81 In school settings, a proposed solution to physical activity promotion and provision of quality physical education is to have physical education specialists in primary schools. A secondary option is to provide sufficient training and up skilling for generalist teachers to undertake this role. However this is cautioned by available evidence which shows there is strong and consistent consensus that generalist classroom teachers lack confidence to teach physical education, feel inadequately trained and prepared and tend to place physical education as a lower priority in an already "crowded" curriculum $(9,10)$. There is also an immediate opportunity with the development of the Australian National HPE curriculum for primary and high schools to place opportunities to develop FMS centre-stage in HPE programs. The public consultation phase for the Draft HPE curriculum has recently closed and it is currently

91 being revised for publication in late 2013. Fortunately it appears that FMS will be one of the key categories in the curriculum's movement and physical activity strand. However, it is unclear whether teachers will have to assess and report student achievement against FMS

94 proficiency. Current practice would suggest this is unlikely (10), but given the evidence, this 95 is what we should be striving for.

96

97 Solutions to address Australian children's lack of mastery in the basic FMS (14, 27-29) needed to lead active healthy lives, requires cooperation and commitment between public

99 health, education and early childhood sectors. There are three priority areas; firstly we need 100 to ensure that FMS development is highlighted in all relevant policy documents; secondly to 
101 ensure that children are given opportunities to be taught FMS during the preschool years and;

102 thirdly ensuring primary schools provide a quality HPE program accompanied by appropriate

103 teacher resources and professional development. We also need all Australian states and

104 territories to monitor children's FMS proficiency through state-wide surveys (such as the

105 NSW SPANS(14)) as this will provide one dimension of children's capacity to participate in

106 a range of physical activities and give us valuable information as to how we are tracking with

107 changing this situation. In the face of disparaging public reports and at a time when we are

108 currently considering a national curriculum now is the opportune time to take action in a

109 timely and coordinated fashion to up-skill our children for a lifetime of physical activity. 


\section{References}

112 1. Hardy LL, Reinten-Reynolds T, Espinel P, Zask A, Okely AD. Prevalence and

113 Correlates of Low Fundamental Movement Skill Competency in Children. Pediatrics. 2012

114 August 1, 2012;130(2):e390-e8.

115 2. Lubans DR, Morgan PJ, Cliff DP, Barnett LM, Okely AD. Review of the benefits

116 associated with fundamental movement skill competency in youth. Sports Medicine.

117 2010;40(12):1019-35.

118 3. Barnett L, van Beurden E, Morgan PJ, Brooks LO, Beard JR. Childhood motor skill

119 proficiency as a predictor of adolescent physical activity. Journal of Adolescent Health.

$120 \quad 2009 ; 44: 252-9$.

121 4. Barnett L, van Beurden E, Morgan PJ, Brooks LO, Beard JR. Does childhood motor 122 skill proficiency predict adolescent fitness? Medicine and Science in Sports and Exercise.

$1232008 ; 40: 2137-44$.

124 5. Ulrich DA. Test of Gross Motor Development (2nd ed). Austin, TX2000.

125 6. Bunker LK. The Role of Play and Motor Skill Development in Building Children's

126 Self-Confidence and Self-Esteem. The Elementary School Journal. 1991;91(5):467-71.

127 7. Barnett L, Hinkley T, Okely AD, Salmon J. Child, family and environmental

128 correlates of children's motor skill proficiency. Journal of science and medicine in sport /

129 Sports Medicine Australia. 2012.

$130 \quad 8 . \quad$ Cools W, Martelaer K, D., Samaey C, Andries C. Fundamental movement skill

131 performance of preschool children in relation to family context. Journal of Sports Sciences $132 \quad 2011 ; 29: 649-60$.

133 9. Morgan PJ, Hansen V. Recommendations to improve primary school PE: the

134 classroom teacher's perspective. The Journal of Educational Research. 2007;101:99-112. 
135 10. Morgan PJ, Hansen V. Classroom teachers' perceptions of the impact of barriers to

136 teaching PE on the quality of PE programs delivered in primary schools. Research Quarterly

137 for Exercise and Sport. 2008;79:506-16.

138 11. Cliff DP, Okely AD, Morgan PJ, Steele JR, Jones RA, Colyvas KIM, et al. Movement

139 Skills and Physical Activity in Obese Children: Randomized Controlled Trial. Medicine \&

140 Science in Sports \& Exercise. 2011;43(1):90-100.

141 12. Morley B, Scully M, Niven P, Baur LA, Crawford D, Flood V, et al. Prevalence and 142 socio-demographic distribution of eating, physical activity and sedentary behaviours among

143 Australian adolescents. Health Promotion Journal of Australia. Accepted 20 August 2012.

144 13. Kohl 3rd HW, Craig CL, Lambert EV, Inoue S, Alkandari JR, Leetongin G, et al. The 145 pandemic of physical inactivity: global action for public health. The Lancet.380(9838):294146305.

147 14. NSW Ministry of Health. NSW Schools Physical Activity and Nutrition Survey

148 (SPANS) 2010 Full Report. Sydney: Centre for Health advancement2011.

149 15. Crawford D, Australian Government Independent Sport Panel. The Future of Sport in 150 Australia2009.

151 16. Australian Government Preventive Health Taskforce. Australia the Healthiest Country 152 by 2020. National Healthy Preventative Health Strategy - the road map for action Canberra 1532009 Contract No.: P3 -5444.

154 17. Senate Standing Committee on Environment Recreation and the Arts. Physical and 155 Sport Education. Canberra: The Parliament of the Commonwealth of Australia1992.

156 18. Department of Health and Ageing. National Physical Activity Recommendations for

157 Children 0-5 Years, Move and Play Every Day. Canberra2010.

158 19. Australian Government Department of Health and Ageing. Get up and Grow Healthy

159 Eating and Physical Activity for Early Childhood2009. 
20. Council of Australian Governments. Early Childhood Development Steering

161 Committee, National Quality Standard for Early Childhood Education and Care and School

162 Age Care: Australian Government 2009 December.

163 21. Adams J, Zask A, Dietrich U. Tooty Fruity Vegie in preschools: an obesity prevention

164 intervention in preschools targeting children's movement skills and eating behaviours. Health

165 Promotion Journal of Australia. 2009;20(2):112-9.

166 22. Zask A, Adams JK, Brooks LO, Hughes DF. Tooty Fruity Vegie: an obesity

167 prevention intervention evaluation in Australian preschools. Health Promotion Journal of

168 Australia. 2012;23(1):10-5.

169 23. Adams J, Molyneux M, Squires L. Sustaining an obesity prevention intervention in

170 preschools. Health Promotion Journal of Australia. 2011;22(1):6-10.

171 24. Zask A, Barnett LM, Rose L, Brooks LO, Molyneux M, Hughes D, et al. Three year

172 follow-up of an early childhood intervention: is movement skill sustained? International

173 Journal of Behavioral Nutrition and Physical Activity. 2012;9(1):127.

174 25. Hardy LL, King L, Kelly B, Farrell L, Howlett S. Munch and Move: evaluation of a

175 preschool healthy eating and movement skill program. International Journal of Behavioral

176 Nutrition \& Physical Activity. 2010;7:80-90.

177 26. Jones R, A., Riethmuller A, Hesketh K, Trezise J, Batterham M, Okely AD.

178 Promoting fundamental movement skill development and physical activity in early childhood

179 settings: A cluster randomized controlled trial. Pediatric Exercise Science. 2011;23:600-15.

180 27. van Beurden E, Zask A, Barnett LM, Dietrich UC. Fundamental movement skills -

181 How do primary school children perform? The 'Move It Groove It' program in rural Australia.

182 Journal of Science and Medicine in Sport. [Journal Article]. 2002;5:244-52.

183 28. Cooley D, Oakman R, McNaughton L, Ryska T. Fundamental Movement Patterns in

184 Tasmanian Primary School Children. Perceptual and Motor Skills. 1997 1997;84:307-16. 
185 29. Hume C, Okely AD, Bagley S, Telford A, Booth M, Crawford D, et al. Does weight

186 status influence associations between children's fundamental movement skills and physical

187 activity? Research Quarterly for Exercise and Sport. 2008;79:158-65.

188

189 